\title{
The Economic Effects of U.S. Presidential Tax Communication
}

T. Philipp Dybowski ${ }^{\dagger}$,J. Nikolaj Dybowski ${ }^{\ddagger}$ and Philipp Adämmer ${ }^{\star}$

$49 / 2016$

${ }^{\dagger}$ Department of Economics, University of Münster, Germany

‡ Department of Bioinformatics, University of Duisburg-Essen, Germany

* Department of Economics, Helmut-Schmidt-University Hamburg, Germany

wissen.leben

WWU Münster 


\title{
The Economic Effects of U.S. Presidential Tax Communication
}

\author{
T.P. Dybowski ${ }^{\mathrm{a}, * *}$, J.N. Dybowski ${ }^{\mathrm{b}}$, P. Adämmer ${ }^{\mathrm{c}}$ \\ ${ }^{a}$ Institute of International Economics, University of Muenster, Universitaetsstr. 14-16, \\ 48143 Muenster, Germany \\ ${ }^{b}$ Department of Bioinformatics, University of Duisburg-Essen, Universitaetsstr. 2, 45117 \\ Essen, Germany \\ ${ }^{c}$ Chair for Applied Stochastics and Risk Management, Helmut-Schmidt-University, \\ Holstenhofweg 85, 22043 Hamburg, Germany
}

\begin{abstract}
Aside from affecting tax expectations, the U.S. President holds a unique position to influence economic sentiment. We apply a probabilistic topic model and a dictionary-based sentiment analysis to extract information on the tone and the prevalence of tax policy in public statements by the U.S. president. Our econometric analyses show that prioritizing tax policy temporarily stimulates consumption, investment, and output. A positive tone in presidential tax news suggests that these results stem from sentiment effects. In accordance, we find that confidence rises and policy uncertainty decreases in response to more precise tax communication. The positive effect on output persists after controlling for tax foresight, underscoring the existence of a distinct sentiment effect.
\end{abstract}

Keywords: tax policy, U.S. president, news, sentiment, topic models

JEL: C32, C82, D72, D83, E61

\footnotetext{
${ }^{*}$ We are indebted to participants of the $9^{t h}$ International Conference on Computational and Financial Econometrics, as well as to Nicole Branger, Bernd Kempa, and Bernd Wilfling for helpful comments. We also thank Todd B. Walker for providing the data for the implicit tax rate.

${ }^{* *}$ Corresponding author

Email addresses: philipp.dybowski@wiwi.uni-muenster.de (T.P. Dybowski), nikolaj.dybowski@uni-due.de (J.N. Dybowski), adaemmer@hsu-hh.de (P. Adämmer)
} 


\section{Introduction}

Economic research has shown that presidential speeches on future tax changes can lead to shifts in expectations, affecting economic activity well ahead of the actual policy implementation (see e.g. Mertens and Ravn, 2011; Mertens and

5 Ravn, 2012, Leeper et al. 2012, Leeper et al., 2013b). Yet, economists have paid scant attention to how presidential tax policy communication impacts economic output via sentiment effects. Blinder and Watson (2016) have recently revived the interest in the U.S. president by investigating why the U.S. economy has consistently performed better during Democratic than during Republican presidencies. We contribute to this strand of literature by analyzing how presidential tax policy announcements evoke sentiment effects and, in turn, affect economic activity.

As the central actor on the political stage, the president receives broad attention which allows him to exert influence on public opinion. This notion is strengthened by empirical findings from Wood et al. (2005) who show that the incumbent can raise sentiment by giving optimistic remarks on the state of the economy. Eshbaugh-Soha (2013) further add to this notion by emphasizing the importance of presidential rhetoric. He shows that news reports, covering presidential press conferences, often use the president's words. With approval ratings in mind, presidents tend to form favorable images of their economic plans. During economic slack, the government enacts stimulus packages and advertises campaigns to signal that the administration is working on improving the economic situation. During economic expansions, presidents try to make sure that the public attributes the economic prosperity to their legislation (De Boef and Kellstedt, 2004). Independent of rhetorical means, presidents also have the ability to direct media attention towards issues that are on the government's political agenda (Miles, 2014).

Measuring policy statements is a difficult task as it requires the quantification of written records. This typically entails two problems. First, the collection and quantification of text data is often costly in terms of time and resources. 
Second, narrative measures are often prone to subjectivity due to their manual compilation (DiMaggio et al., 2013, Grimmer and Stewart, 2013).

To overcome these difficulties and to introduce the analysis of presidential tax communication to economics, we apply Latent Dirichlet Allocation (LDA) 35 by Blei et al. (2003). LDA is a probabilistic topic model developed in the field of computational linguistics. It enables us to analyze 97,819 presidential documents with regards to their tax policy content. LDA is especially suitable for text analyses as it is automated, explicit, inductive and recognizes the relationality of meaning. This means that the algorithm can process a bulk of data (automated), generate a reproducible data set for other researchers (explicit), without providing prior information on the structure of the corpus (inductive). It further allows terms to vary in meaning across different contexts DiMaggio et al. 2013). LDA has recently found its way into economic research, mainly to analyze the effects of central bank communication on economic performance 45 (see, e.g., Fligstein et al., 2014, Acosta, 2015; Hansen and McMahon, 2016).

We use LDA to construct a measure that indicates to what extent a presidential document is related to tax policy issues. Since tax announcements most likely affect spending and investment decisions, we first investigate the impact of tax speeches on GDP and its constituents. We then investigate two transmission channels through which these announcements may affect the economy, namely consumer confidence and policy uncertainty.

Our approach is related to Wood et al. (2005), but differs in three distinct respects. First, in contrast to analyzing general economic statements, we identify tax policy relevant documents. This is an important difference as tax policy changes entail prospects of changing disposable income and thus have a direct effect on economic sentiment. Second, we expand the analysis to the effects of tax announcements on policy uncertainty measures since a decrease in tax policy uncertainty can have a positive effect on economic activity (see, e.g., Fernández-Villaverde et al., 2015). Finally, compared to a word-count algo-

${ }_{60}$ rithm, our approach is less prone to subjectivity when it comes to selecting the relevant tax policy speeches. 
To analyze the effects of presidential tax news we extend the structural vector-autoregressive (SVAR) frameworks of Blanchard and Perotti (2002) and Leeper et al. (2013b). The impulse response analyses show that output, private consumption and investment react positively to a rise in our tax policy news measure. A subsequent analysis shows that the positive stimulus persists even after controlling for tax foresight.

In conjunction with the transitory dynamics in output, private consumption, and investment, these results are suggestive of sentiment effects. A dictionarybased analysis (see, e.g., Hansen and McMahon, 2016) confirms that presidents adopt a positive tone in their announcements to convey a favorable image of their tax policy. Building on these findings, we show that confidence rises and economic policy uncertainty declines after more precise tax communication. Both channels can account for temporary increases in consumption, investment and

putput (see, e.g., Angeletos et al. 2014, Huo and Takayama, 2015, FernándezVillaverde et al. 2015; Ahmed and Cassou, 2016).

The remainder of this paper is organized as follows. Section 2 explains LDA and our data retrieval process. Section 3 presents the econometric framework as well as our empirical results. Section 4 concludes.

\section{Latent Dirichlet Allocation}

Latent Dirichlet Allocation (LDA) is an algorithm that belongs to a class of so called probabilistic topic models which enable the computational analysis of written texts. LDA assumes that documents are distributions over topics, where each topic is a distribution over words (Blei, 2012).

Assume that a corpus consists of $K$ pre-determined topics, $D$ documents and $\mathrm{N}$ words where each document is a vector of $n$ words $(\mathbf{w})$. Under these assumptions a blank document $d$ is filled by iterating over three steps:

1. $\theta_{d} \sim \operatorname{Dir}(\alpha)$

Topic proportions are drawn from a dirichlet distribution that is parameterized by a vector $\alpha$. This first step sets the document's content. 


\section{2. $z_{n} \sim$ Multinomial $\left(\theta_{d}\right)$}

Each word is randomly assigned to one topic. The higher the proportion for a certain topic, the higher the probability that a word gets assigned to it.

3. $w_{n} \mid z_{n}, \beta_{1: K} \sim$ Multinomial $\left(\beta_{k}\right)$

Given the topic assignment $\left(z_{n}\right)$ and all topics $\left(\beta_{1: K}\right)$, the word is randomly drawn from the topic it was assigned to.

The following joint distribution of the hidden $(\beta, \theta$ and $z)$ and observed $(w)$ variables summarizes the dependencies outlined in the generative process:

$$
p\left(\beta_{1: K}, \theta_{1: D}, z_{1: D}, w_{1: D}\right)=\prod_{i=1}^{K} p\left(\beta_{i}\right) \prod_{d=1}^{D} p\left(\theta_{d}\right)\left(\prod_{n=1}^{N} p\left(z_{d, n} \mid \theta_{d}\right) p\left(w_{d, n} \mid \beta_{1: K}, z_{d, n}\right)\right) .
$$

The only observed data for statistical inference are the words. To reveal the hidden variables from given documents, LDA reverses the generative process, asking which hidden structure most likely generated the observed documents (Blei, 2012).

An important feature of LDA is that it reveals hidden topics without additional information on the collection of documents, such as topic labels, classifications or annotations. The sole data input is a document-term-frequency matrix that records the occurrences of all words in each document. Based on this data, LDA automatically reveals a pre-specified number of topics that best fits the generative process of the documents.

\subsection{Data retrieval and preparation for $L D A$}

Our source for presidential documents is The American Presidency Project, an pnline resource dedicated to the study of the U.S. Presidency by Woolley and Peters (2015). This corpus contains thousands of presidential speeches, radio addresses, State of the Union addresses, inaugural speeches, press conferences and statements from the White House. 
We use an automated algorithm to collect each document from 1945 to 2015 together with metadata. For each speech, we record the date, the title and the speaker, along with an ID that uniquely identifies each document (see Table 1).

$$
\text { [TABLE } 1 \text { ABOUt HeRE.] }
$$
contained in the corpus, we ran the algorithm with 50, 75, 100, and 150 topics. A calibration of 100 topics yields the best-behaved topics with respect to the outlined trade-off. 
Table 3 gives an excerpt of eight topics revealed by LDA. For each topic, we show the 20 most likely words in descending order of probability within that topic. Since LDA finds topics solely based on relational occurrences of words, each topic is solely given a number from 1 to 100 (topic order has no significance). It is up to the researcher to make meaning of each topic (DiMaggio et al. 2013). For illustrative purposes, we have added the following headlines: Tax policy, Government spending, Legislation, Political parties, Health care, Civil rights, Freedom, and US armed forces. Our choice for headlines is based on those words that appear with high probability within each topic.

\subsection{Constructing a monthly tax news measure}

A visual inspection of Table 3 shows the high cohesiveness of words within each topic. As the aim of this paper is to study the effects of tax policy news on macroeconomic aggregates, we choose topic 27 as our tax topic since it comprises words like tax, income, pay, or taxpayer with high probability.

To analyze the prevalence of tax policy news over time, we construct a consecutive time series that we label tax policy news measure (TPNM). Following Griffiths and Steyvers (2004), we use the results from LDA to compute topic proportions for each document. This is done by counting how many times a word in a document was assigned to topic 27 . The resulting time series has 97,819 observations (i.e. number of documents), which occur at different intervals as presidential announcements do not necessarily occur on a daily basis. To obtain a monthly time series, we select that document that exhibits the highest tax topic proportion per month. We refrain from averaging over all documents within a month as a large number of presidential public papers do not address tax issues. The large number of documents that are silent on tax issues (i.e., tax topic proportion close to zero) would bias the time series towards zero. Aside from this technical reason, our approach is supported by findings from political science which show that the president's unique position ensures that a single 
announcement often suffices to draw attention by the press and the public (see,

\section{Empirical application of the presidential tax news measure}

Having constructed and validated our TPNM, we are interested in its effect on output and its constituents. For this, we build on the fiscal policy SVAR of Blanchard and Perotti (2002) and extend the model with our tax policy news et al. (2013b). Finally, we investigate two possible transmission channels in which presidential tax announcements affect confidence and economic policy uncertainty.

\footnotetext{
${ }^{1}$ For legislation of tax reforms after 2005, we use information published on www.congress.gov.

${ }^{2}$ Appendix B provides econometric results that further validate our TPNM in regards to its tax content.
} 


\subsection{The effects of presidential tax news on output}

${ }_{200}$ We begin with the SVAR framework of Blanchard and Perotti (2002), that uses quarterly data on total tax revenues $\left(T_{t}\right)$, government spending $\left(G_{t}\right)$ and output $\left(X_{t}\right)$ to investigate the dynamic effects of tax shocks on the U.S. economy. The structural model with four lags has the following form,

$$
Y_{t}=\beta^{\prime} \mathbf{Y}_{t-1}+\delta^{\prime} d_{t}+\mathcal{B} \varepsilon_{t}
$$

where $Y_{t}=\left[T_{t}, G_{t}, X_{t}\right]^{\prime}$ contains the observables. $\mathbf{Y}_{t-1}=\left[Y_{t-1}^{\prime}, \ldots, Y_{t-p}^{\prime}\right]^{\prime}$ is a vector of lagged variables with autoregressive coefficients matrix $\beta, p$ is the number of lags, $d_{t}$ contains deterministic terms with coefficients $\delta$. $\mathcal{B}$ is a matrix of contemporaneous coefficients, and $\varepsilon_{t}=\left[\varepsilon_{t}^{T}, \varepsilon_{t}^{G}, \varepsilon_{t}^{X}\right]$ is the vector of structural shocks, with $E\left[\varepsilon_{t}\right]=0, E\left[\varepsilon_{t} \varepsilon_{t}^{\prime}\right]=I$, and $E\left[\varepsilon_{t} \varepsilon_{s}^{\prime}\right]=0$ for $s \neq t$. The reduced form residuals $u_{t}=\left[u_{t}^{T}, u_{t}^{G}, u_{t}^{X}\right]$, by assumption, are linearly linked to the structural shocks,

$$
u_{t}=\mathcal{B} \varepsilon_{t}
$$

Standard estimation methods yield consistent estimates for $\beta, \delta, u_{t}$ and $E\left[u_{t} u_{t}^{\prime}\right]$ (Lütkepohl, 2005). According to (3) the reduced-form covariance matrix can be expressed as,

$$
E\left[u_{t} u_{t}^{\prime}\right]=\mathcal{B} E\left[\varepsilon_{t} \varepsilon_{t}^{\prime}\right] \mathcal{B}^{\prime}=\mathcal{B B}^{\prime}
$$

which can be recovered from the estimation of (2). This system contains six free parameters in $\mathcal{B}$ due to the symmetry of $E\left[u_{t} u_{t}^{\prime}\right]$. Three additional restrictions on parameters in $\mathcal{B}$ uniquely identify the system. To formalize these restrictions, Blanchard and Perotti (2002) express the reduced form errors as

$$
\begin{aligned}
& u_{t}^{T}=a_{G} \varepsilon_{t}^{G}+a_{Y} u_{t}^{Y}+\varepsilon_{t}^{T} \\
& u_{t}^{G}=b_{T} \varepsilon_{t}^{T}+b_{Y} u_{t}^{Y}+\varepsilon_{t}^{G} \\
& u_{t}^{X}=c_{T} u_{t}^{T}+c_{G} u_{t}^{G}+\varepsilon_{t}^{X},
\end{aligned}
$$


where $a_{G}, b_{T}$ measure the interdependence of government spending and tax revenues. $a_{Y}, b_{Y}$ represent the dependence of tax revenues and government spending on unexpected movements in output, and $c_{T}, c_{G}$ capture the contemporaneous dependence of output to fiscal policy instruments.

Blanchard and Perotti (2002) draw on institutional information about the U.S. tax and transfer systems. That is, decision lags in fiscal policy and recognition lags in economic activity rule out discretionary fiscal policy in responses to changes in output within the same quarter. $a_{Y}$ and $b_{Y}$ thus represent automatic feedback from economic activity to fiscal policy, which are determined outside of the VAR. They estimate $a_{Y}=2.08$ as the average output elasticity of taxes, and set $b_{Y}=0$, as there is no automatic feedback from output to government spending. Finally, there is no contemporaneous dependence of taxes to government spending so that $a_{G}=0$. These three restrictions solve the system for the remaining parameters $b_{T}, c_{T}, c_{G}$ and exactly identify the structural impulse responses. This system can be estimated using the residuals of the tax and government spending equations as instruments for the regressors in the output equation (Blanchard and Perotti, 2002).

To quantify the effects of presidential tax policy news on output, we augment the system of reduced-form errors in (5) with an equation for our tax policy news measure $\left(N_{t}\right)$ :

$$
\begin{aligned}
& u_{t}^{T}=a_{G} \varepsilon_{t}^{G}+a_{Y} u_{t}^{Y}+a_{N} u_{t}^{N}+\varepsilon_{t}^{T} \\
& u_{t}^{G}=b_{T} \varepsilon_{t}^{T}+b_{Y} u_{t}^{Y}+b_{N} u_{t}^{N}+\varepsilon_{t}^{G} \\
& u_{t}^{X}=c_{T} u_{t}^{T}+c_{G} u_{t}^{G}+c_{N} u_{t}^{N}+\varepsilon_{t}^{X} \\
& u_{t}^{N}=d_{T} u_{t}^{T}+d_{G} u_{t}^{G}+d_{X} u_{t}^{X}+\varepsilon_{t}^{N},
\end{aligned}
$$

where $a_{N}, b_{N}$ and $c_{N}$ are the contemporaneous dependencies of taxes, government spending and output on tax policy news, and $d_{T}, d_{G}, d_{X}$ measure the immediate dependence of tax policy news on taxes, government spending and output, respectively. To achieve identification, we follow Leeper et al. (2013a) 
and make three reasonable assumptions in addition to those of Blanchard and Perotti (2002). Namely, that tax policy news have no immediate impact on current tax revenues $\left(a_{N}=0\right)$, government spending $\left(b_{N}=0\right)$ and output $\left(c_{N}=0\right)$. This identification scheme implies that structural tax and spending shocks of (6) exactly coincide with those of (5). Together, the six restrictions exactly identify the structural shocks of system (6), including the structural tax news shock and its effects on the economy. The unrestricted coefficients $d_{i}$ can again be estimated via the instrument variable approach described above.

We estimate model (6) using quarterly data from the BEA's NIPA tables and quarterly averages of our presidential tax policy news measure for the sample 1954Q1 to 2007Q4. Total tax revenues are defined as general government current tax receipts and contributions for government social insurance. Government spending is defined as general consumption expenditures and gross government investment net of purchases of nonproduced assets and less consumption of fixed capital. Output is defined as gross domestic product (GDP). All macroeconomic variables are in logarithms of real per capita terms. As in Blanchard and Perotti (2002), we include a constant, linear and quadratic trends, a dummy for 1975:II and its four lags, and quarter-dependent macroeconomic aggregates that account for seasonal patterns.

We report transformed impulse response functions that represent multipliers in the vein of Blanchard and Perotti (2002). Each multiplier signifies a dollar response to a dollar shock in the fiscal variable. Following Leeper et al. (2013b), we apply the tax revenue data to scale the impulse responses to a tax news shock. If not indicated otherwise, impulse responses are reported with $90 \%$ confidence intervals computed by Monte-Carlo simulations with 1000 replications.

Figure 3 , shows the results from the estimation of (6). From left to right, panels show the response of output to a tax increase, the response of output to 265 an increase in presidential tax policy news, and the response of presidential tax policy news to a tax increase.

[Figure 3 about here.] 
Consistent with previous studies, an increase of taxes reduces output. The output multiplier is just under -1 on impact and grows in magnitude over the course of five quarters, reaching a negative peak response of about -1.4, before decaying towards the end of the horizon.

Our main interest lies in the responses of output to our tax policy news measure. During the first three quarters after a tax policy news shock output reacts with a positive response. The peak response is reached after three quarters at about 0.12. After that, influence of presidential tax policy news vanishes and does not have a long run effect on output.

\subsection{The effects of presidential tax news on consumption and investment}

To further investigate the transmission channel of tax news to output, we follow a strategy proposed by Blanchard and Perotti (2002) to extend the SVAR in (6). Sequentially, we add an equation with private consumption and investment as components of GDP to the system. Following Blanchard and Perotti (2002), we order the component of GDP whose response we are studying after GDP. Under consideration of the restrictions imposed on (6) and four additional assumptions that shut down the immediate impact of the output component on tax revenues $\left(a_{X_{c}}=0\right)$, government spending $\left(b_{X_{c}}=0\right)$, output $\left(c_{X_{c}}=0\right)$, and tax news $\left(d_{X_{c}}=0\right)$, the relation between residuals and structural innovations becomes

$$
\begin{aligned}
u_{t}^{T} & =a_{Y} u_{t}^{Y}+\varepsilon_{t}^{T} \\
u_{t}^{G} & =b_{T} \varepsilon_{t}^{T}+\varepsilon_{t}^{G} \\
u_{t}^{X} & =c_{T} u_{t}^{T}+c_{G} u_{t}^{G}+\varepsilon_{t}^{X} \\
u_{t}^{X} & =f_{T} u_{t}^{T}+f_{G} u_{t}^{G}+\varepsilon_{t}^{X_{c}} \\
u_{t}^{N} & =d_{T} u_{t}^{T}+d_{G} u_{t}^{G}+d_{X} u_{t}^{X}+d_{X_{c}} u_{t}^{X_{c}}+\varepsilon_{t}^{N},
\end{aligned}
$$

where $X_{c}$ indicates either private consumption or investment as components of GDP.

Figure 4 shows the responses of the output components to a tax news shock (left column) and to a tax revenue shock (right column). Consistent with the 
findings in Blanchard and Perotti (2002), an increase in taxes induces a reduction in both private consumption and investment.

[Figure 4 about here.]

In contrast to the adverse effects of a tax shock, increased tax policy news by the president temporarily increase both private consumption and investment. Whereas private consumption is modestly stimulated for a period of three quarters, the positive effect on private investment is comparatively strong and longer lasting (six quarters). These results corroborate the findings of a positive effect on output.

\subsection{Controlling for tax foresight}

Aside from the necessity to expand the set of conditioning variables in a VAR by fiscal expectations to recover the true (unexpected) structural tax shock (Leeper et al. 2013a), we want to control for news on future expected tax changes for a second reason. Empirical findings from Leeper et al. (2013b) and Mertens and Ravn (2012) reveal that expected tax increases cause economic activity to rise temporarily. These findings are consistent with intertemporal substitution effects, triggered during the preimplementation phase of announced tax increases.

300

Presidential speeches are an obvious source for information on future tax changes. As our presidential TPNM is constructed on these sources, it could be correlated with information on anticipated tax changes. However, our TPNM only captures the presidential priority for tax policy but not the direction of future tax changes. To avoid this potential misinterpretation and isolate the effects of anticipated tax changes, we need to control for such.

We follow Leeper et al. (2013b) and control for anticipated tax changes in the SVAR model (6) by including the 'implicit tax rate' as fifth variable. The implicit tax rate reflects expected tax changes that are implied by the yield spread between tax exempt municipal bonds and taxable government bonds. 
that the implicit tax rate does not affect the system contemporaneously.

[Figure 5 about here.] interpreted as an anticipated tax increase, stimulates output significantly for about 7 quarters. This is consistent with findings from Leeper et al. (2013b) and Mertens and Ravn (2012) and can be explained by intertemporal substitution effects. More importantly, we find that the temporary positive effect from increased presidential tax news persists. Thus, the temporary positive effect is no spurious anticipated tax effect caused by coincidental correlation of our

\subsection{Investigating transmission channels of sentiments}

The preceding results show that explicit tax policy statements by the president increase economic activity in the short run via stimulating private consumption and investment. The question remains: What are the transmission channels through which these announcements affect private consumption and investment? A likely channel is the perception of tax policy and its effect on people's beliefs about future economic conditions. In this respect, confidence and uncertainty are two possible determinants of overall sentiment that are likely to ¡e affected by presidential announcements (see, e.g., Wood et al., 2005, Blinder 330 and Watson, 2016).

Presidential speeches are political instruments. Therefore, presidents will try to use speeches to impose positive interpretations of the economy and advertise policy measures directed to improve economic conditions (De Boef and Kellstedt, 2004). In a multitude of presidential documents we find evidence for such 335 rhetoric. For example, there is talk of: "sustained economic growth and job creation", "enable taxpayers to plan for their future with more confidence", "help

\footnotetext{
${ }^{3}$ Appendix $\mathrm{C}$ shows that the output multipliers estimated in Sections $3.1,3.2$ and 3.3 are robust to different calibrations of the output elasticity of tax revenues.
} 
millions of American families", "relief is on the way", "the President's plan is fair", "provide certainty to middle-class families", "closing unfair loopholes", "make ours the land of the future, offering unlimited opportunity", "ensure a full economic recovery", etc 4 All of these quotes clearly target people's economic perception in an attempt to improve sentiment, foster a feeling of security or the sense of fairness. If such positive rhetoric predominates tax policy statements it could be effective in raising sentiment, which in turn, boosts short term consumption and investment (see, e.g., Blinder and Watson, 2016).

To investigate whether tax policy announcements are characterized by a positive tone, we conduct a sentiment analysis based on a dictionary of positive and negative sentiment words by Liu et al. (2005) 5 In the style of Hansen and McMahon (2016), we measure the relative difference of positive and negative sentiment words in the 844 tax policy statements that comprise our TPNM as

$$
\operatorname{RelSent}_{d}=\frac{\left(w_{n, d}^{\text {pos }}-w_{n, d}^{\text {neg }}\right)}{w_{n, d}^{\text {total }}} .
$$

$w_{n, d}^{p o s}\left(w_{n, d}^{n e g}\right)$ is the count of words within a document belonging to the positive (negative) sentiment list and $w_{n, d}^{\text {total }}$ is the total count of words in the respective tax policy document. Accordingly, RelSent ${ }_{\mathrm{d}}$ is placed in the interval $[-1,1]$, with realizations $>0$ indicating a positive sentiment and $<0$ a negative sentiment within a document.

[Figure 6 about here.]

The histogram for the relative sentiment measure is depicted in Figure 6 It shows that the mean for all 844 tax policy relevant documents is positive with RelSent $_{\text {mean }}=0.059$. In addition, a one-sided t-test with a t-value of 25.42 strongly rejects the null hypothesis $\mathrm{H}_{0}:$ RelSent $_{\text {mean }} \leq 0$, stating that tax policy statements by presidents adopt a positive tone on average. The question

\footnotetext{
${ }^{4}$ See Appendix A for a list of exemplary quotes from presidential tax policy documents.

"The "directional" word lists for sentiments can be downloaded via: https://www.cs.uic. edu/ liub/FBS/opinion-lexicon-English.rar
} 
that remains is whether this optimistic tone has a positive influence on people's economic perceptions.

\subsubsection{The role of confidence}

To shed light on the previous notion, we investigate the influence of our presidential tax policy measure on confidence. For this exercise, we use the Conference Board's Consumer Confidence Index. It represents a widely followed monthly measure for public confidence in the economy (Ludvigson, 2004). Thus, we can analyze the direct effects of presidential tax policy announcements on consumer confidence. Ideally, we would want to include the consumer confidence index in our SVAR analyses and study the transmission channel within the entire framework. Unfortunately, the index only exists since 1967:2. Including it would require the aggregation to quarterly data from 1967:2 to 2007:12, thereby eliminating about $25 \%$ of our observations while simultaneously increasing the number of variables in our model. This seems undesirable when analyzing the effects in SVAR frameworks of five and more variables (see, e.g., Auerbach and Gorodnichenko, 2012).

Instead, we use our original monthly measure for presidential tax policy news and the monthly confidence index and estimate a bi-variate VAR under two different lag specifications, $p=1$ and $p=6 \sqrt{6}$ We include a constant,a trend and control for the legislative lags of documented tax reforms as documented in Yang (2007) and information taken from www.congress.gov for tax reforms after 2005. Due to the construction of our TPNM and the confidence survey design, we assume no contemporaneous correlation between tax news and consumer confidence. This is justified since each observation of the TPNM represents the one speech per month with the highest tax topic proportion. Meanwhile, responses to the Conference Board's survey flow in throughout the survey month (Ludvigson, 2004). In the extreme case of a presidential speech held on the 31st

\footnotetext{
${ }^{6}$ The majority of lag length criteria opt for a lag length of $p=1$. Given the monthly frequency of the data we also estimated the VARs with $p=6$ lags to cover half a year.
} 
of a month, there is no way that consumers could have taken this speech into account when filling out the survey for the given month.

[Figure 7 about here.]

The left column of Figure 7 presents impulse responses of consumer confidence to a $1 \%$ point increase in the presidential TPNM for the two different lag specifications. The right column shows the respective cumulative impulse responses. Gray shaded areas denote one standard deviation confidence intervals. Under both lag specifications, consumer confidence responds positively to the shock in presidential tax policy announcements. The positive effect, although smaller in magnitude, has a lasting effect for the model with $p=1$ lags, while for $p=6$ lags the response becomes insignificant after 6 months. In the model with $p=6$ the cumulative effect of a $1 \%$ point increase in a speech's tax policy probability amounts to a 0.41 index points increase of the confidence index after six months. To put this magnitude into perspective, note that the average tax policy statement in our sample has a topic proportion of $11.1 \%$. In contrast, a speech with a loud and clear tax policy message such as Ronald Reagan's "Radio Address to the Nation on Tax Reform" held on April 13, 1985, exhibits a tax policy proportion of $40.3 \%$. If such a speech were to follow on a phase in which tax policy was rather ambient noise in the presidents policy agenda, this would amount to an increase of 11.9 points in the consumer confidence index over the course of half a year.

Such arguments are in line with Angeletos et al. (2014) or Huo and Takayama (2015), who show that news shocks can create waves of optimism concerning the short-term economic outlook that lead to a transitory boom in consumption, investment, and output.

\subsubsection{The role of policy uncertainty}

As noted by Blinder and Watson (2016) uncertainty and confidence are sometimes viewed as two sides of the same coin. If people gain confidence regarding future economic conditions due to repeated statements by the president adver- 
tising, e.g., a "fairer tax system", "future economic growth" or a "bright future with more confidence", this should be reflected in lower uncertainty.

To test this notion, we draw on the monthly economic uncertainty indexes by Baker et al. (2016). Among others, it contains monthly indexes for fiscal and tax policy uncertainty. This data allows us to study the effects of presidential statements on uncertainty surrounding related policy fields.

Similar to the consumer confidence data, the monthly categorized uncertainty measures are only available for a subsample starting in 1985:1. Therefore, we follow the same approach as in Section 3.4.1 and use our monthly TPNM together with the uncertainty indexes for tax and fiscal policy and estimate two bi-variate VARs 7 Again, we include a constant, a trend and control for the legislative lags of documented tax reforms. Analogously to Section 3.4.1, we postulate that no contemporaneous correlation between tax news and policy uncertainty exists. A relevant presidential speech could have been held at the 31 st of a month, whereas the policy uncertainty indexes are compiled as aggregate monthly counts of newspaper articles containing policy uncertainty related key words.

Figure 8 shows the impulse responses of tax policy uncertainty and fiscal policy uncertainty to a $1 \%$ point increase in our presidential tax policy news measure for two different lag specifications 8 Results show that an increase of the tax policy news content in presidential speeches by $1 \%$ point lowers the tax and fiscal policy uncertainty indexes by roughly 0.5 index points after two months and around 1 index point after three months. Accumulated, a 1\% point increase of the tax topic in presidential speeches lowers tax policy uncertainty

\footnotetext{
${ }^{7}$ Including these indexes in the SVAR frameworks, would require the aggregation to quarterly data from 1985:1 to $2007: 12$, thereby eliminating more than half of the observations while simultaneously increasing the number of variables in our model.

${ }^{8}$ The majority of lag length criteria opt for a lag length of $p=4$. Given the monthly frequency of the data we also estimated the VARs with $p=6$ lags to cover half a year.
} 
by 3.80 index points $(p=6)$ and fiscal policy uncertainty by 3.87 index points after six months (see Figure 9).

These results can be explained by the fact that the indexes count those articles containing word quadruplets which include words in regards to economic policy and the words "uncertainty" or "uncertain". As such, these measures should be lower subsequent to an informative tax policy statement by the president (Eshbaugh-Soha, 2013).

Our findings provide an additional explanation why the TPNM stimulates economic activity temporarily: More informative statements on tax policy reduces policy uncertainty. This, in turn, is a likely cause for the temporary boost of private consumption, investment and output. Such arguments are consistent with findings of Fernández-Villaverde et al. (2015), who show conversely that an increase in volatility (i.e. uncertainty) of capital income tax induces a fall in output, consumption, and investment in the short run.

[Figure 9 about here.]

\section{Conclusion}

Modern economies are characterized by a close interaction between politics and economics. As the central actor on the political stage, the president holds a unique position to influence public opinion through his policy communication. We apply a probabilistic topic model to construct a measure that captures the tax policy priority of the president over time. In addition, a dictionary-based sentiment analysis reveals the tone in the presidential tax policy statements.

Our impulse response analyses show that a positive shock in our measure stimulates output temporarily. The stimulus can be explained by increased private consumption and investment. The positive effect on output persists after controlling for tax foresight, suggesting the existence of a distinct sentiment effect. To shed light on this notion, we investigate two sentiment-driven transmission channels through which tax policy communication may influence economic activity: consumer confidence and policy uncertainty. We find that 
a shock in our measure increases consumer confidence, which can be explained by the positive rhetoric adopted in presidential tax policy statements. In accordance, we find that presidential speeches reduce policy uncertainty as expressed 475 in newspaper articles. This mitigates the known adverse effects on consumption, investment and output stemming from policy uncertainty. 


\section{References}

Acosta, M. (2015). FOMC Responses to Calls for Transparency. Finance and Economics Discussion Series 2015-60, Board of Governors of the Federal Reserve System (U.S.).

Ahmed, M. I. and Cassou, S. P. (2016). Does consumer confidence affect durable goods spending during bad and good economic times equally? Journal of Macroeconomics, 50:86 - 97 .

Angeletos, G.-M., Collard, F., and Dellas, H. (2014). Quantifying Confidence. NBER Working Papers 20807, National Bureau of Economic Research, Inc.

Auerbach, A. J. and Gorodnichenko, Y. (2012). Measuring the output responses to fiscal policy. American Economic Journal: Economic Policy, 4(2):1-27.

Baker, S. R., Bloom, N., and Davis, S. J. (2016). Measuring economic policy uncertainty. The Quarterly Journal of Economics, 131(4):1593.

Blanchard, O. and Perotti, R. (2002). An Empirical Characterization of the Dynamic Effects of Changes in Government Spending and Taxes on Output. The Quarterly Journal of Economics, 117(4):1329-1368.

Blei, D. M. (2012). Probabilistic Topic Models. Communications of the ACM, $55(4): 77-84$.

Blei, D. M. and Lafferty, J. D. (2009). Topic models. In Srivastava, A. N. and Sahami, M., editors, Text Mining: Classification, Clustering, and Application, pages 71-94. Taylor and Francis, London.

Blei, D. M., Ng, A. Y., and Jordan, M. I. (2003). Latent Dirichlet Allocation. Journal of Machine Learning Research, 3:993-1022.

Blinder, A. S. and Watson, M. W. (2016). Presidents and the us economy: An econometric exploration. American Economic Review, 106(4):1015-45. 
Caldara, D. and Kamps, C. (2012). The Analytics of SVARs: A Unified Framework to Measure Fiscal Multipliers. FEDS Working Paper No. 2012-20.

De Boef, S. and Kellstedt, P. M. (2004). The Political (and Economic) Origins of Consumer Confidence. American Journal of Political Science, 48(4):633-649.

DiMaggio, P., Nag, M., and Blei, D. (2013). Exploiting affinities between topic modeling and the sociological perspective on culture: Application to newspaper coverage of U.S. government arts funding. Poetics, 41(6):570 - 606.

Eshbaugh-Soha, M. (2013). Presidential Influence of the News Media: The Case of the Press Conference. Political Communication, 30(4):548-564.

Fernández-Villaverde, J., Guerròn-Quintana, P., Kuester, K., and RubioRamìrez, J. (2015). Fiscal volatility shocks and economic activity. American Economic Review, 105(11):3352-84.

Fligstein, N., Brundage, J. S., and Schultz, M. (2014). Why the federal reserve failed to see the financial crisis of 2008: The role of "macroeconomics" as a sense making and cultural frame. Technical report, IRLE Working Paper No.111-14.

Griffiths, T. L. and Steyvers, M. (2004). Finding scientific topics. Proceedings of the National Academy of Sciences, 101:5228-5235.

Grimmer, J. and Stewart, B. M. (2013). Text as Data: The Promise and Pitfalls of Automatic Content Analysis Methods for Political Texts. Political Analysis, pages $1-31$.

Hansen, S. and McMahon, M. (2016). Shocking language: Understanding the macroeconomic effects of central bank communication. Journal of International Economics, 99, Supplement 1:S114 - S133. 38th Annual NBER International Seminar on Macroeconomics.

Huo, Z. and Takayama, N. (2015). Higher order beliefs, confidence, and business cycles. Technical report, miméo, Yale University. 
Leeper, E. M., Richter, A. W., and Walker, T. B. (2012). Quantitative effects of fiscal foresight. American Economic Journal: Economic Policy, 4(2):115-144.

Leeper, E. M., Walker, T. B., and Yang, S.-C. S. (2013a). Fiscal Foresight and Information Flows. Econometrica, 81(3):1115-1145.

Leeper, E. M., Walker, T. B., and Yang, S.-C. S. (2013b). Supplement to "Fiscal Foresight And Information Flows". Econometrica, 81(3):1115-1145.

${ }_{535} \mathrm{Liu}, \mathrm{B} ., \mathrm{Hu}, \mathrm{M}$, and Cheng, J. (2005). Opinion observer: Analyzing and comparing opinions on the web. In Proceedings of the 14th International Conference on World Wide Web, WWW '05, pages 342-351, New York, NY, USA. ACM.

Ludvigson, S. C. (2004). Consumer confidence and consumer spending. The Journal of Economic Perspectives, 18(2):29-50.

Lütkepohl, H. (2005). New Introduction to Multiple Time Series Analysis. Springer Verlag Berlin Heidelberg.

Mertens, K. and Ravn, M. O. (2011). Understanding the aggregate effects of anticipated and unanticipated tax policy shocks. Review of Economic Dynamics, 14(1):27-54. Special issue: Sources of Business Cycles.

Mertens, K. and Ravn, M. O. (2012). Empirical Evidence on the Aggregate Effects of Anticipated and Unanticipated US Tax Policy Shocks. American Economic Journal: Economic Policy, 4(2):145-81.

Mertens, K. and Ravn, M. O. (2014). A reconciliation of SVAR and narrative estimates of tax multipliers. Journal of Monetary Economics, 68, Supplement:S1 - S19. Supplement issue: October 19-20, 2012 Research Conference on "Financial Markets, Financial Policy, and Macroeconomic Activity".

Miles, M. R. (2014). The Bully Pulpit and Media Coverage: Power without Persuasion. The International Journal of Press/Politics, 19(1):66-84. 
${ }_{555}$ Pereira, M. C. and Lopes, A. S. (2014). Time-varying fiscal policy in the U.S. Studies in Nonlinear Dynamics and Econometrics, 18(2):157-184.

Wood, B. D., Owens, C. T., and Durham, B. M. (2005). Presidential rhetoric and the economy. Journal of Politics, 67(3):627-645.

Woolley, J. T. and Peters, G. (2015). The American Presidency Project.

${ }_{560}$ Yang, S.-C. S. (2007). A Chronology Of Postwar U.S. Federal Income Tax Policy. Indiana University Bloomington Economics Department Center for Applied Economics and Policy Research (CAEPR) Working Paper, 21.

Zeidenstein, H. G. (1984). News Media Perceptions of White House News Management. Presidential Studies Quarterly, 14(3):pp. 391-398. 
Table and figures

Table 1: Excerpt from metadata of the Public Papers of the Presidents, May 1945

\begin{tabular}{|c|c|c|c|c|}
\hline No. & ID & Date & Speaker & Title \\
\hline 70 & 12247\&st\&st1 & May 7, 1945 & Harry S. Truman & Statement $[\ldots]$ on the $[\ldots]$ German Surrender \\
\hline 71 & $87030 \& s t \& s t 1$ & May 8, 1945 & Harry S. Truman & Proclamation 2651 - Victory in Europe \\
\hline 72 & 77941\&st\&st1 & May 8, 1945 & Harry S. Truman & Executive Order $9549[\ldots]$ \\
\hline 73 & 12248\&st\&st 1 & May 8, 1945 & Harry S. Truman & The President's News Conference on V-E Day \\
\hline 74 & 12241\&st\&st1 & May 8, 1945 & Harry S. Truman & Broadcast $[. .$.$] Surrender of Germany$ \\
\hline 75 & $12239 \&$ st\&st 1 & May 8, 1945 & Harry S. Truman & Statement by the President $[\ldots]$ \\
\hline 76 & 12240\&st\&st1 & May 8, 1945 & Harry S. Truman & Messages to Allied Leaders [...] \\
\hline 77 & 87031\&st\&st1 & May 9,1945 & Harry S. Truman & Proclamation $2652[\ldots]$ \\
\hline 78 & 12237\&st\&st1 & May 9,1945 & Harry S. Truman & Statement by the President Upon [...] \\
\hline 79 & 77876\&st\&st1 & May 10,1945 & Harry S. Truman & Executive Order $9550[\ldots]$ \\
\hline 80 & $12236 \&$ st\&st 1 & May 15,1945 & Harry S. Truman & The President's News Conference \\
\hline$\ldots$ & $\ldots$ & . & 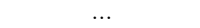 & $\ldots$ \\
\hline
\end{tabular}

Table 2: Descriptive statistics for the corpus of presidential public papers

\begin{tabular}{lccccc}
\hline Documents & Years covered & Documents & Words & Mean & Std.Dev. \\
\hline Raw & $01 / 1945-04 / 2015$ & 97,819 & $114,238,073$ & 1,168 & 2,011 \\
Prepared & $01 / 1945-04 / 2015$ & 97,819 & $42,755,140$ & 437 & 736 \\
\hline
\end{tabular}

The number of unique words in the prepared corpus $=67,133$. 
Table 3: Selection of eight topics revealed by LDA

\begin{tabular}{|c|c|c|c|c|c|c|c|}
\hline \multicolumn{2}{|c|}{$\begin{array}{c}\text { Tax policy } \\
{[\text { topic } 27]}\end{array}$} & \multicolumn{2}{|c|}{$\begin{array}{c}\text { Government spending } \\
{[\text { topic } 100]}\end{array}$} & \multicolumn{2}{|c|}{$\begin{array}{c}\text { Legislation } \\
{[\text { topic } 58]}\end{array}$} & \multicolumn{2}{|c|}{$\begin{array}{c}\text { Political parties } \\
{[\text { topic } 84]}\end{array}$} \\
\hline prob. & words & prob. & words & prob. & words & prob. & words \\
\hline .062 & $\operatorname{tax}$ & .083 & budget & .140 & bill & .069 & republican \\
\hline .041 & income & .056 & spending & .115 & legislation & .064 & campaign \\
\hline .041 & taxes & .038 & cut & .078 & congress & .062 & party \\
\hline .039 & pay & .037 & deficit & .058 & passed & .060 & election \\
\hline .025 & raise & .036 & billion & .044 & pass & .047 & vote \\
\hline .022 & credit & .029 & fiscal & .039 & house & .046 & democrats \\
\hline .019 & plan & .029 & cuts & .039 & sign & .043 & democratic \\
\hline .019 & lower & .021 & $\operatorname{tax}$ & .037 & senate & .040 & republicans \\
\hline .018 & relief & .020 & money & .036 & signed & .020 & candidates \\
\hline .015 & rates & .019 & dollars & .033 & act & .020 & elected \\
\hline .013 & proposal & .018 & debt & .026 & bipartisan & .020 & candidate \\
\hline .012 & burden & .017 & reduction & .022 & bills & .019 & running \\
\hline .012 & revenue & .017 & reduce & .022 & administration & .018 & issues \\
\hline .012 & save & .016 & federal & .021 & legislative & .018 & win \\
\hline .012 & rate & .016 & spend & .018 & veto & .017 & politics \\
\hline .012 & paid & .016 & government & .013 & action & .016 & voted \\
\hline .012 & low & .015 & balanced & .013 & signing & .014 & political \\
\hline .011 & middle & .013 & programs & .013 & pleased & .014 & votes \\
\hline .011 & higher & .013 & balance & .010 & measure & .013 & democrat \\
\hline .011 & taxpayers & .012 & taxes & .010 & compromise & .013 & voters \\
\hline \multicolumn{2}{|c|}{$\begin{array}{c}\text { Health care } \\
{[\text { topic } 85]}\end{array}$} & \multicolumn{2}{|r|}{$\begin{array}{l}\text { Civil rights } \\
{[\text { topic } 45]}\end{array}$} & \multicolumn{2}{|c|}{$\begin{array}{l}\text { Freedom } \\
{[\text { topic } 35]}\end{array}$} & \multicolumn{2}{|c|}{$\begin{array}{c}\text { US armed forces } \\
{[\text { topic } 37]}\end{array}$} \\
\hline prob. & words & prob. & words & prob. & words & prob. & words \\
\hline .035 & health & .121 & rights & .054 & freedom & .054 & military \\
\hline .034 & insurance & .076 & human & .038 & free & .038 & forces \\
\hline .031 & care & .063 & civil & .029 & peace & .032 & army \\
\hline .029 & costs & .049 & society & .020 & strength & .030 & war \\
\hline .021 & coverage & .033 & groups & .018 & history & .029 & armed \\
\hline .019 & cost & .029 & equal & .017 & liberty & .024 & service \\
\hline .018 & medical & .028 & opportunity & .017 & nations & .023 & veterans \\
\hline .017 & medicare & .026 & religious & .014 & power & .023 & force \\
\hline .015 & benefits & .022 & black & .014 & war & .019 & commander \\
\hline .015 & plan & .018 & discrimination & .014 & nation & .018 & air \\
\hline .014 & plans & .015 & church & .014 & live & .015 & uniform \\
\hline .014 & quality & .015 & faith & .014 & values & .015 & navy \\
\hline .013 & affordable & .013 & women & .013 & principles & .015 & chief \\
\hline .011 & access & .012 & race & .013 & human & .013 & duty \\
\hline .010 & doctors & .012 & equality & .013 & independence & .011 & serving \\
\hline .010 & provide & .012 & religion & .012 & peoples & .011 & soldiers \\
\hline .010 & patients & .011 & participate & .012 & seek & .011 & guard \\
\hline .010 & hospital & .010 & racial & .011 & hope & .011 & corps \\
\hline .009 & system & .009 & justice & .010 & common & .010 & naval \\
\hline .009 & prescription & .009 & womens & .009 & struggle & .010 & women \\
\hline
\end{tabular}


Memorandum of Disapproval of Bill Repealing the Admissions Tax on

Motion Picture Performances.
Statement by the President Upon Signing the Revenue Act.
Special Message to the Congress Message to the Congress

on Reform of the Federal Tax Outlining 1977 Tax System.
Dutlining 1977 Tax
Letter to the Chairman, Senate
Committee on Finance, on the
Memorandum of Disapproval of
Presidential Statement No. 7
Address to the Nation on Bill Amending the Interna on Economic Issues: Improving
Federal Tax and Spending
Tax Reduction and Revenue Code of 1954 the Tax System. Reductions.
Reform Message to the Need for an Increase in Taxes.
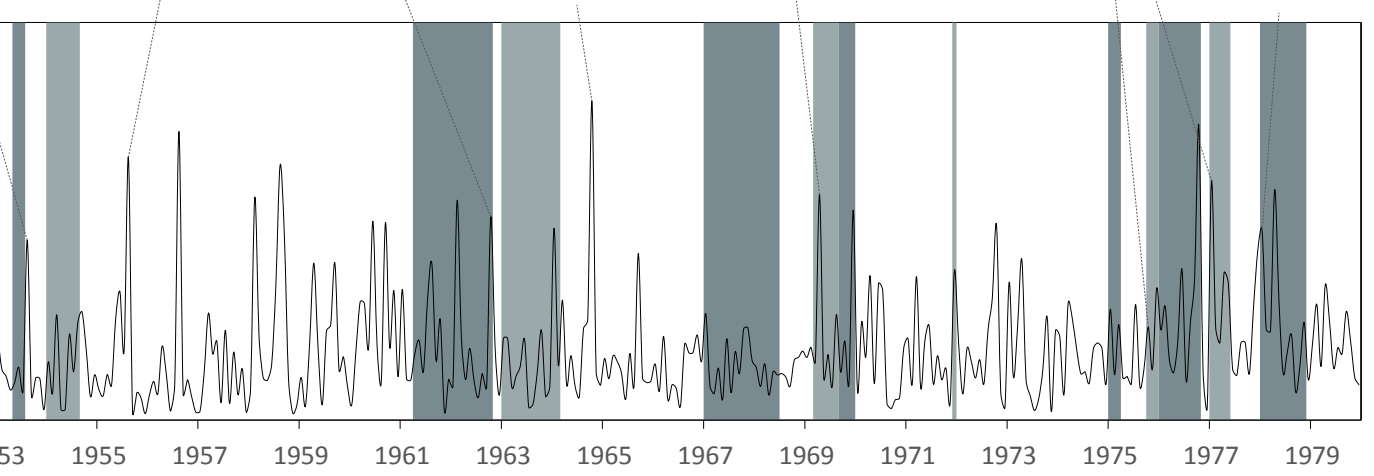

Legislative lag Legislative lag _ Probabilities

Figure 1: Time series of presidential tax news topic probability at monthly frequency for the period 1945 to 1979 . It is defined as the percentage of topic 27 word occurences in the document which yields the highest percentage during the respective month. The shaded areas mark the legislative lags of U.S. tax reforms as documented in Yang (2007). Different shadings have no meaning other than to differentiate between tax reforms. 
Radio Address to the Nation on Tax Reform
Remarks on the Economic Program and an Exchange With Reporters
H.R. 4275 - Permanent Extension of

10 Percent Individual Income Tax Rate Bracket
Fact Sheet: Recovery Act

Tax Relief
Statement on Federal
White House Fact Sheet on the
Proposed Savings and Economic
Fact Sheet: President's Tax Relief
Plan Gives Greatest Relief to
Obama Says Middle Class Tax H.R. 8 - Job Protection and Relief Plan Will Give Working Recession Prevention Act Growth Act of 1990
Lowest Income Taxpayers Americans a Break of 2012

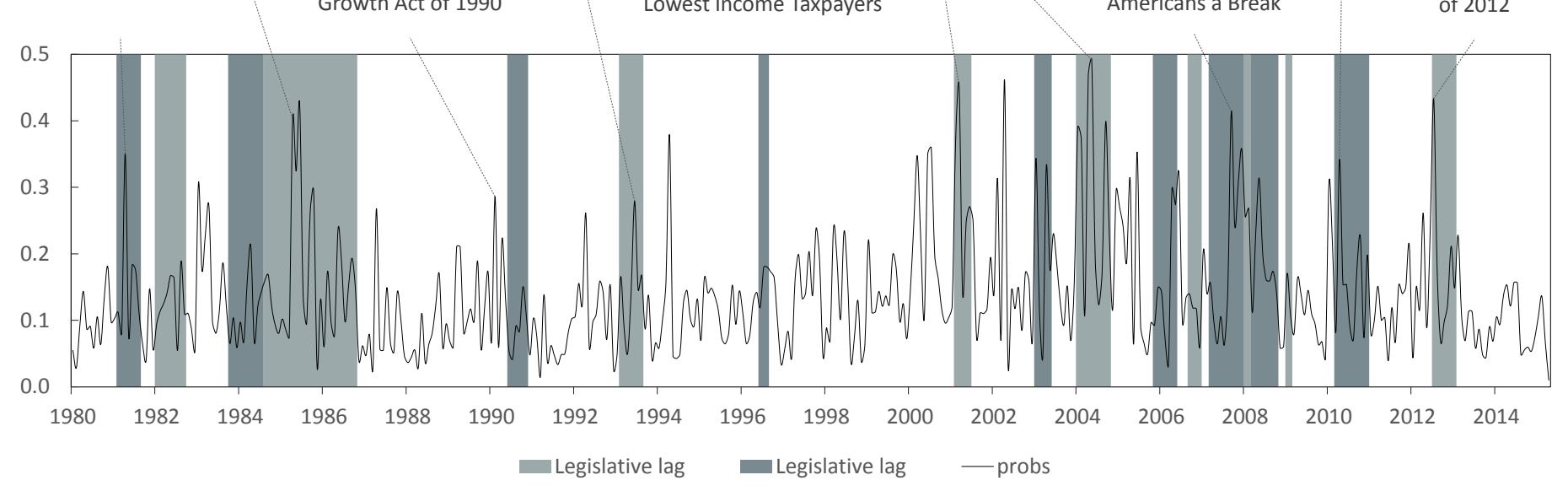

Figure 2: Time series of presidential tax news topic probability at monthly frequency for the period 1980 to 2015 . It is defined as the percentage of topic 27 word occurences in the document which yields the highest percentage during the respective month. The shaded areas mark the legislative lags of U.S. tax reforms as documented in Yang (2007). Different shadings have no meaning other than to differentiate between tax reforms. 

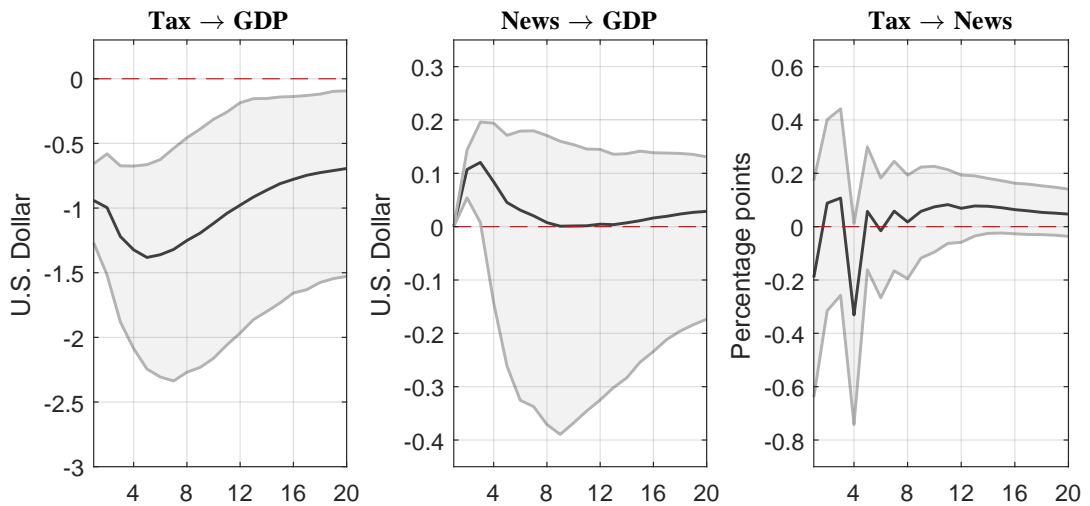

Figure 3: Impulse responses to a $\$ 1$ increase in taxes and a $1 \%$ point increase of tax policy news from the SVAR in 6 with $a_{Y}^{B P}=2.08$. BP denotes a calibration of the output elasticity of tax revenues according to Blanchard and Perotti (2002). Shaded regions are the 90 percent confidence intervals, based on Monte Carlo simulation with 1000 iterations (assuming normality). 

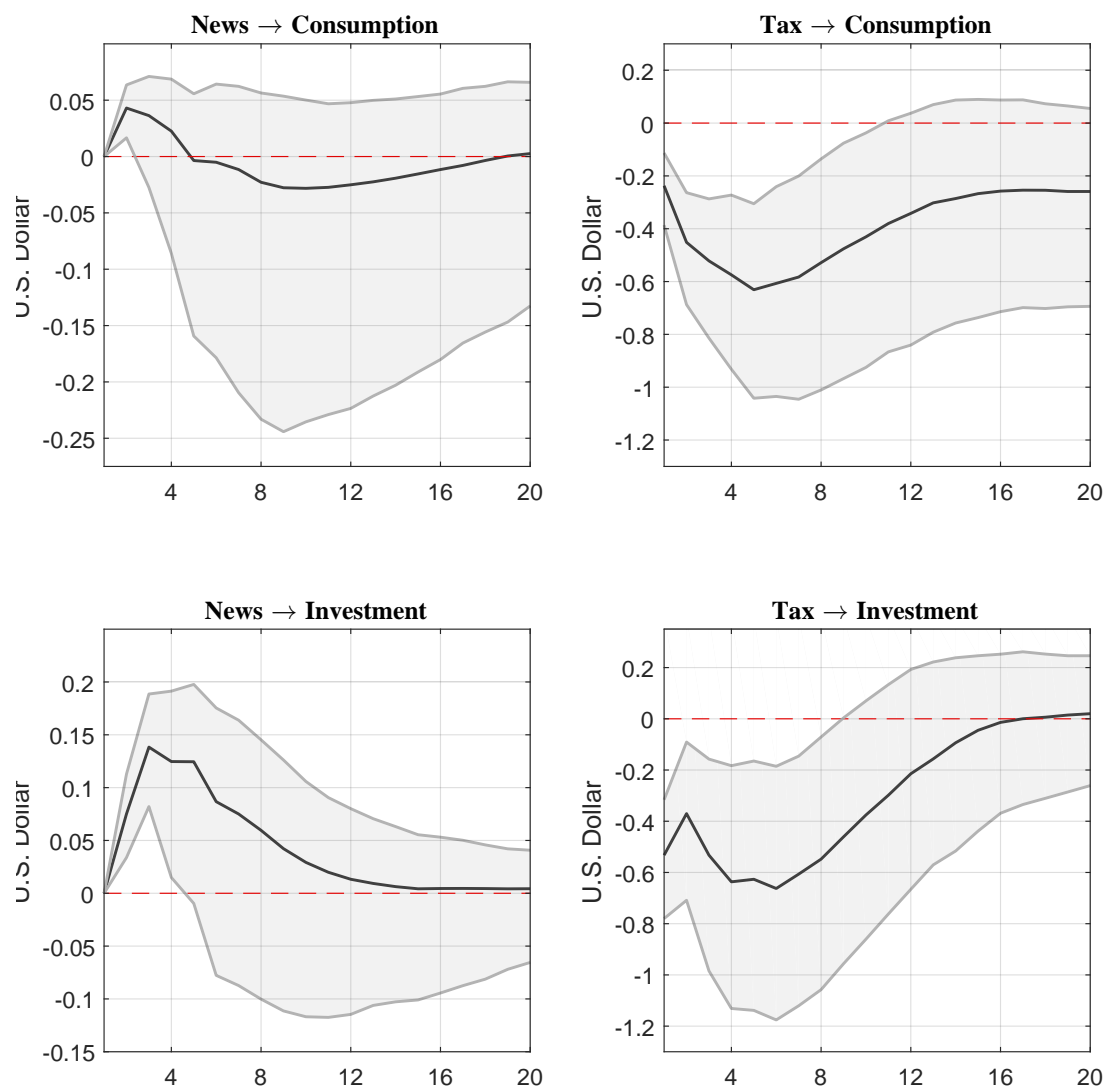

Figure 4: Impulse responses to a $1 \%$ point increase of tax policy news and a $\$ 1$ increase in taxes from the SVAR extension in 77 with $a_{Y}^{B P}=2.08$. BP denotes a calibration of the output elasticity of tax revenues according to Blanchard and Perotti (2002). Shaded regions are the 90 percent confidence intervals, based on Monte Carlo simulation with 1000 iterations (assuming normality). 

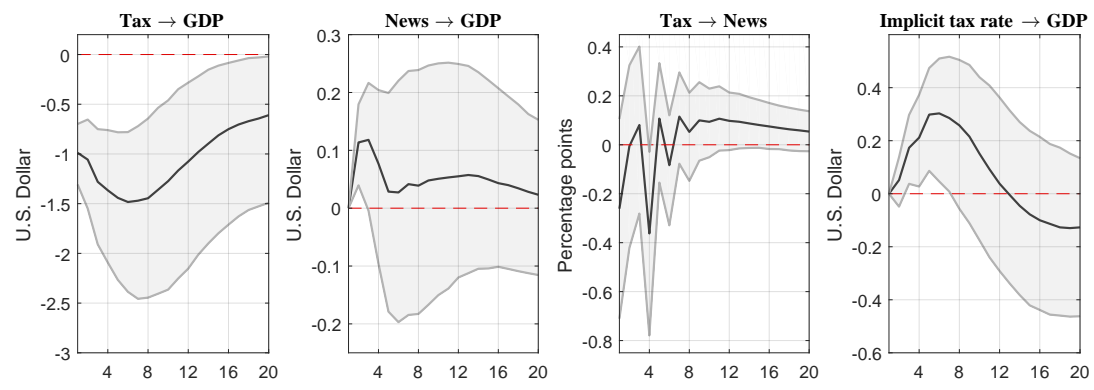

Figure 5: Impulse responses to a $\$ 1$ increase in taxes, $1 \%$ point increase of tax policy news, and $\$ 1$ increase in anticipated taxes from the SVAR specification using the implicit tax rate to control for foresight (see, Leeper et al. 2013b) and $a_{Y}^{B P}=2.08$. BP denotes a calibration of the output elasticity of tax revenues according to Blanchard and Perotti (2002). Shaded regions are the 90 percent confidence intervals, based on Monte Carlo simulation with 1000 iterations (assuming normality).

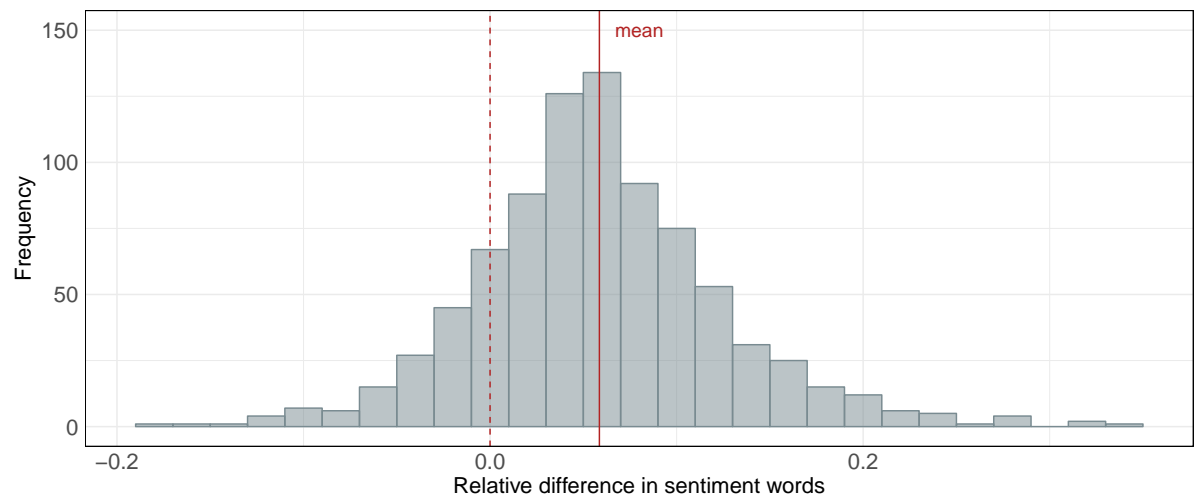

Figure 6: Histogram of the relative difference of sentiment words in the 844 monthly tax documents that comprise the TPNM. 

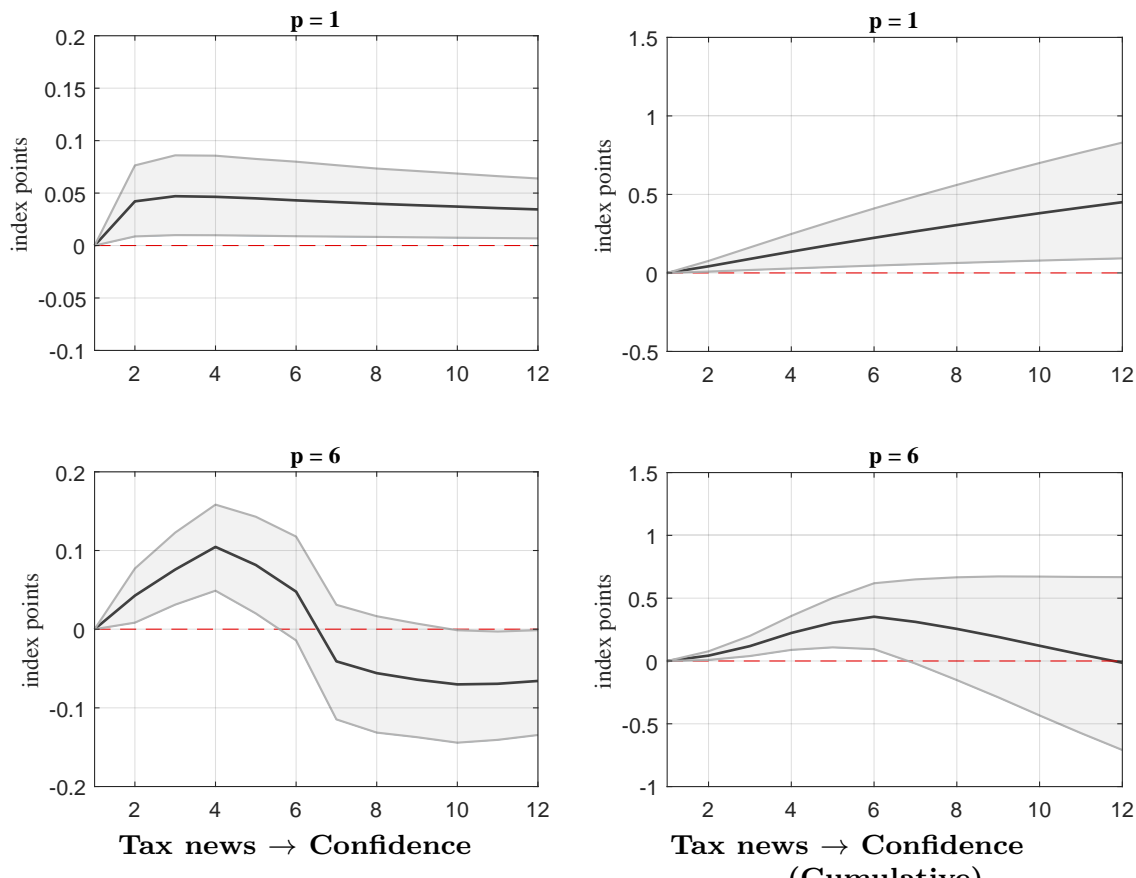

Figure 7: (Cumulative) impulse responses of the confidence index (The Conference Board) to a $1 \%$ point increase in the tax policy news measure in bi-variate $\operatorname{VAR}(\mathrm{p})$ models under alternative lag lengths p. Shaded regions signify one standard deviation confidence intervals, based on Monte Carlo simulation with 1000 iterations (assuming normality). 

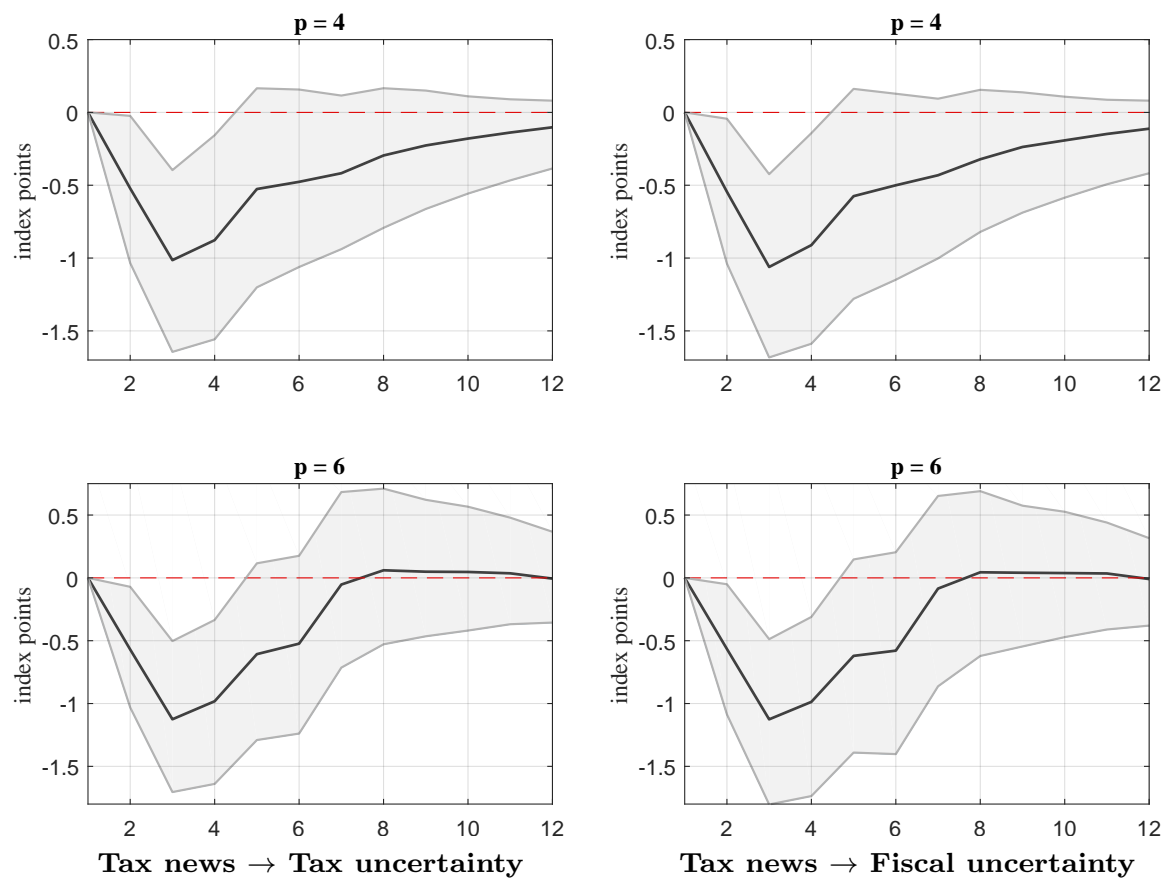

Figure 8: Impulse responses of tax and fiscal policy uncertainty indexes to a $1 \%$ point increase in the tax policy news measure in bi-variate $\operatorname{VAR}(\mathrm{p})$ models under alternative lag lengths $\mathrm{p}$. Shaded regions are the 90 percent confidence intervals, based on Monte Carlo simulation with 1000 iterations (assuming normality). 

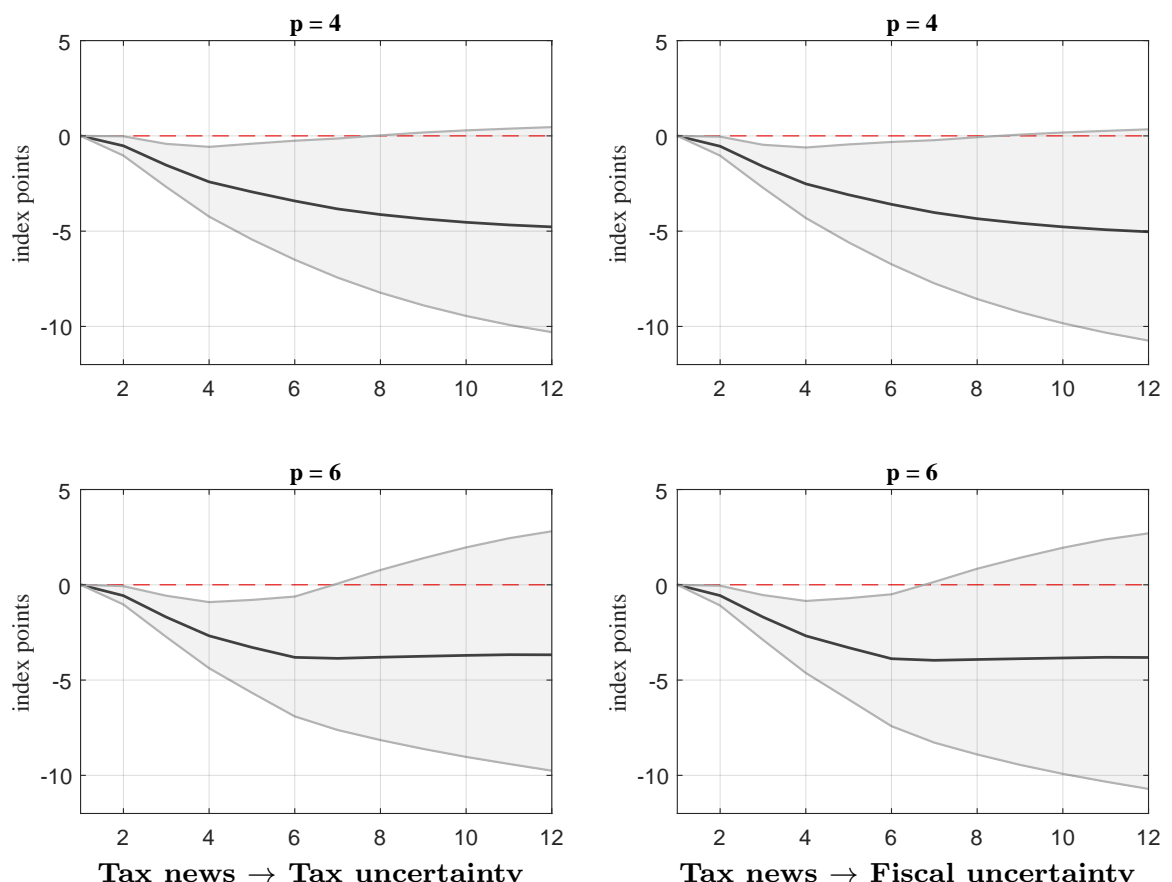

Figure 9: Cumulative impulse responses of tax and fiscal policy uncertainty indexes to a $1 \%$ point increase in the tax policy news measure in bi-variate $\operatorname{VAR}(\mathrm{p})$ models under alternative lag lengths p. Shaded regions are the 90 percent confidence intervals, based on Monte Carlo simulation with 1000 iterations (assuming normality). 


\title{
A. Selected quotes from presidential speeches with high tax policy relevance
}

\author{
[Table 5 about here.]
}

\section{B. Additional validation of the monthly tax news measure} sions in the vein of DiMaggio et al. (2013). Specifically, we regress the monthly word count for topic 27 on a dummy variable that marks the legislative lag of documented tax reforms $(=1)$. We control for the overall attention to tax related words in presidential documents (i.e., tax words in a context other than topics. Column I of table 4 shows the results.

\section{[Table 4 about here.]}

We find that presidential documents contain, on average, 205 words more from topic 27 during legislative lags than in non-reform periods. As the timing of legislative lags is based on information external to our data set, this adds to the validity of our interpretation for topic 27 .

Regressions II and III further refine the analysis. To ensure that the tax topic is actually a policy topic and not distorted by loosely related tax issues, such as the president's annual tax return, we control for fiscal policy related words. Hence, we regress the monthly word count for our tax topic on the word count of a fiscal policy topic (see Table 3, topic 100). Results in column II show that the quantity of words from topic 100 has a positive and significant effect on the occurrence of words from topic 27 in each document. For every two words more related to fiscal policy (e.g., words like budget, spending, fiscal, or deficit), a given document will also contain one additional word related to the tax topic. These results underline that topic 27 actually forms a tax policy measure. Results from column III further corroborate these findings and serve as an additional robustness check. 
On a more technical note, an important feature of our measure is its ability to identify tax policy relevant documents that are seemingly irrelevant at first glance. This results from the strength of the LDA algorithm to identify thematic structures in documents compared to simpler word counting algorithms or subjective hand-selection (DiMaggio et al., 2013). One example is President Reagan's "Remarks at the Great Valley Corporate Center in Malvern, Pennsylvania" (May 31, 1985), in which he stated to "[...] have a new tax plan that [...], all Americans will like". This document does not mention the word tax in its headline. Consequently, any algorithm that scans headlines for tax related words to identify relevant documents, and likely any researcher browsing through headlines by hand, would miss this speech. LDA, however, attributes 185 words to the tax policy topic, making up for 32.4 percent of all words in that speech. Imagine a scenario in which a speech like this was picked up by news agents at the time and processed through the media, eventually affecting people's tax policy perceptions. Thirty years later, a researcher not aware of this speech's content disregards this document, rendering his data set with less informational content than that of individuals at that time.

\section{Robustness to alternative output elasticities of taxes calibrations}

Recently, the sensitivity of output multipliers to different calibrations of the output elasticity of tax revenues $a_{Y}$ has given rise to debate. Caldara and Kamps (2012) show that the effects on output hinge critically on the estimated elasticity of tax revenues to output. Loosely speaking, the elasticity scales the output multiplier upwards or downwards depending on its size. Low values for $a_{Y}$ result in smaller multipliers, whereas greater values for $a_{Y}$ yield larger multipliers. For very low estimates of $a_{Y}$ tax shocks even result in a positive effect on output, as the positive correlation between tax revenues and output is not sufficiently controlled for. Following up on this finding, Mertens and Ravn (2014) propose an alternative approach for the estimation of $a_{Y}$. By integrating narrative measures that are correlated with tax shocks but uncorrelated to other structural 
shocks, they propose a higher estimate for the elasticity with $a_{Y}=3.13$ which result in higher output multipliers consistent with narrative studies.

To assure that our results are robust to different calibrations for the output elasticity of tax revenues, we re-estimate all previous SVAR specifications using different values for $a_{Y}$. Specifically, we use the higher estimate $a_{Y}^{M R}=3.13$ proposed by Mertens and Ravn (2014) and a compromise value $a_{Y}^{P L}=2.2$ estimated by Pereira and Lopes (2014).

Figure 10 depicts the results for the SVAR model in (6). As expected, the effect of the positive tax shock on output is greater in magnitude compared to Figure 3, with $a_{Y}^{B P}=2.08$. All other results remain completely unaffected. Output reacts positively to an increase in the presidential tax policy news variable for the first three quarters. As in the benchmark, tax revenues do not cause any effect in the tax news variable.

[Figures 11 and 12 about here.]

The same holds for the SVAR extension in $(7)$, when using the two alternative calibrations for output elasticity of tax revenues. Figure 11 shows the 640 results for $a_{Y}^{M R}=3.13$ and Figure 12 shows the results for $a_{Y}^{P L}=2.2$. As expected, the higher elasticities scale up the effects on both output components. Yet, results remain unchanged. A tax increase lowers private consumption and investment, while an increase in the TPNM positively affects both consumption and investment.

${ }_{645}$ Finally, Figure 13 plots the results from the SVAR model with tax foresight. The two alternative calibrations for $a_{Y}$ have the previously discussed scaling effect on the output multiplier, without altering the narrative. Results stemming from presidential tax policy news are unchanged.

[Figure 13 about here.] 
Table 4: Validity tests for the tax policy news variable (Appendix B

Estimation method: Cochrane-Orcutt regression

Dependent variable: Number of words assigned to monthly tax topic Sample (monthly): Januar 1945 - April 2015

\begin{tabular}{lccc} 
& \multicolumn{3}{c}{ Regressions } \\
& I. & II. & III. \\
\cline { 2 - 4 } Tax reform dummy & $205^{* *}$ & & $152^{* *}$ \\
& $(5.89)$ & & $(4.74)$ \\
Fiscal policy phrases & & $0.526^{* *}$ & $0.507^{* *}$ \\
& & $(15.84)$ & $(15.35)$ \\
Other topic phrases & $0.014^{* *}$ & $0.008^{* *}$ & $0.008^{* *}$ \\
& $(27.98)$ & $(12.64)$ & $(13.47)$ \\
\hline Durbin-Watson statistic & 2.137 & 2.149 & 2.144 \\
Adjusted $R^{2}$ & 0.486 & 0.571 & 0.582 \\
\hline
\end{tabular}

The table presents Cochrane-Orcutt regression results as validity tests for our interpretation of topic 27 as tax policy news. ${ }^{* *}$ indicates $p \leq 0.01$. 
Table 5: Selected quotes from presidential speeches with high tax policy probability

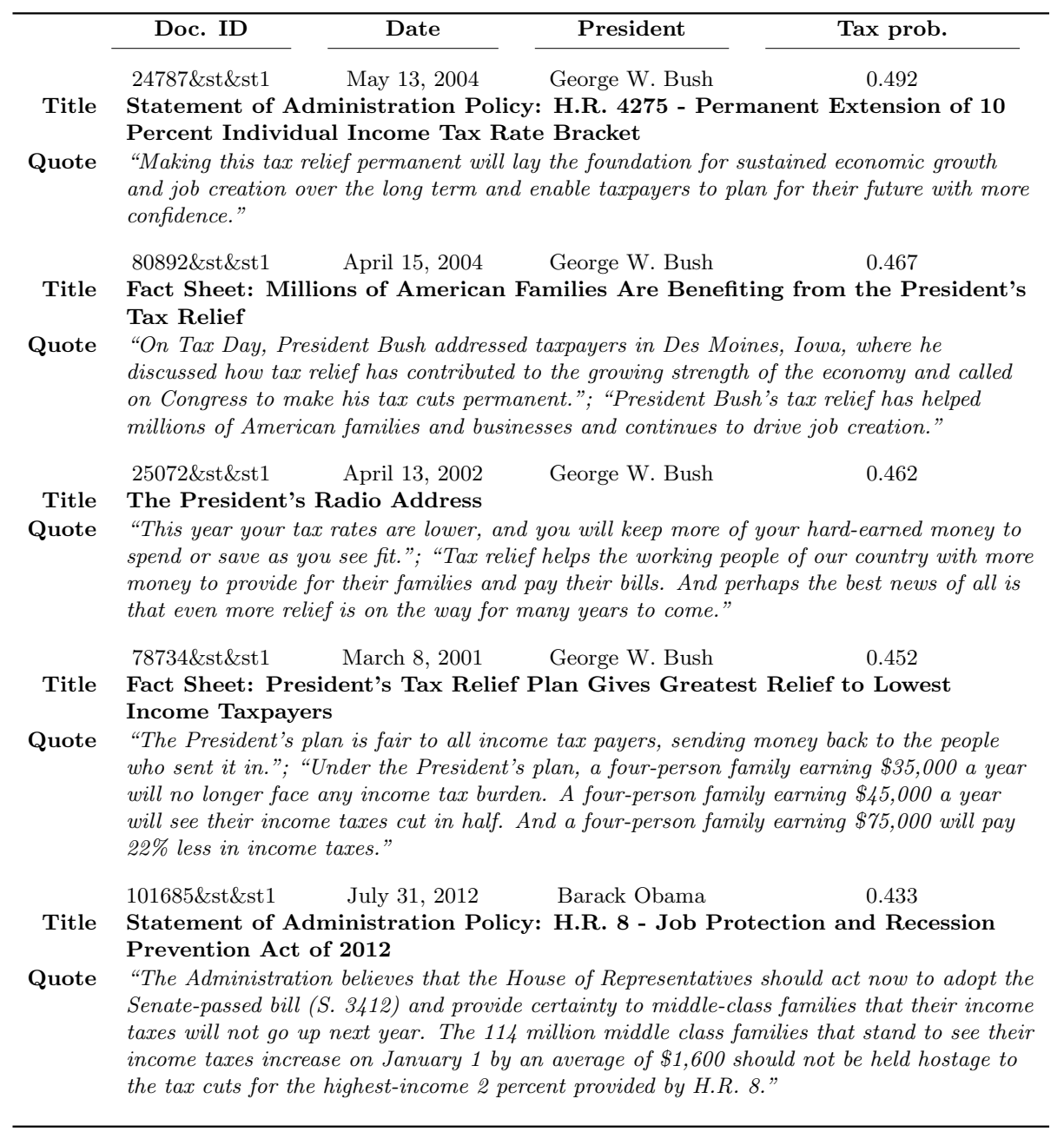

Continued on next page. 
(continued)

\begin{tabular}{|c|c|c|c|}
\hline Doc. ID & Date & President & Tax prob. \\
\hline 38829\&st\&st1 & June 27, 1985 & Ronald Reagan & 0.426 \\
\hline
\end{tabular}

Title Remarks to State and Local Officials During a White House Briefing on Tax Reform

Quote "The key idea in our proposal is that by ironing out the complexities and closing unfair loopholes, by making everyone pay their fair share, we can make the system more equitable and dramatically lower marginal tax rates without a loss in revenue."; "In other words, our fair share plan is also a progrowth tax plan."; "In the end, all America will benefit from this fairer, progrowth tax plan."
38463\&st\&st1
April 13, 1985
Ronald Reagan
0.403

Title Radio Address to the Nation on Tax Reform

Quote "With your support, this will be the last year the American people face today's high tax barriers. We'll propose reducing sharply personal tax rates, bringing the top rate down to 35 percent or lower, and providing most Americans a tax cut."; "We can create a new tax code-clean, simple, and fair. We can make ours the land of the future, offering unlimited opportunity to all Americans who dare to live for their dreams."

26678\&st\&st1 October 28, $1964 \quad$ Lyndon B. Johnson

0.401

Title Presidential Statement No. 7 on Economic Issues: Improving the Tax System

Quote "THIS administration carried through the most extensive overhaul of our tax system since the war. The improvements have made our tax systems fairer, and have strengthened the economy."

81260\&st\&st1 September 2, $2004 \quad$ George W. Bush

0.399

Title Fact Sheet: President Bush Provides Leadership on Tax Reform

Quote "President Bush believes that America's taxpayers deserve, and our future economic prosperity demands, a simpler, fairer, pro-growth system - and he has pledged to lead a bipartisan effort to reform and simplify the tax code."

81533\&st\&st1 January 10, $2004 \quad$ George W. Bush 0.390

Title Fact Sheet: President Bush Urges Congress to Make Tax Cuts Permanent

Quote "During his weekly radio address, President Bush called upon Congress to make his tax cuts permanent and discussed his plan to create jobs in America and ensure a full economic recovery."

59909\&st\&st1 April 12, $1994 \quad$ William J. Clinton

0.378

Title Press Briefing by Secretary of Treasury Lloyd Bentsen

Quote "For every American whose tax rates increase because of deficit reduction, 12 more will see a cut in their taxes."; "It's just plain wrong that income taxes are going up for a great many Americans - 98.8 percent of all taxpayers this year have no changes in their income tax rates."
80738\&st\&st1
February 9, 2004
George W. Bush
0.373

Title Fact Sheet: Tax Relief Is Strengthening Our Economy

Quote "[...] enabling families and businesses to plan for the future with confidence by making tax reductions permanent"; "In the past three years, President Bush has proposed and signed into law three bills reducing the tax burden on American families and small businesses to spur savings, investment, and job creation."

The table presents selected quotes from presidential speeches which have high probability under the tax policy topic. We show the corresponding document title to each quote, along with addition metadata. This includes the unique ID, allowing to find the speech on www.presidency.ucsb.edu, the date on which the speech was given, the president giving the speech, and the probability of this speech to be tax policy relevant. 

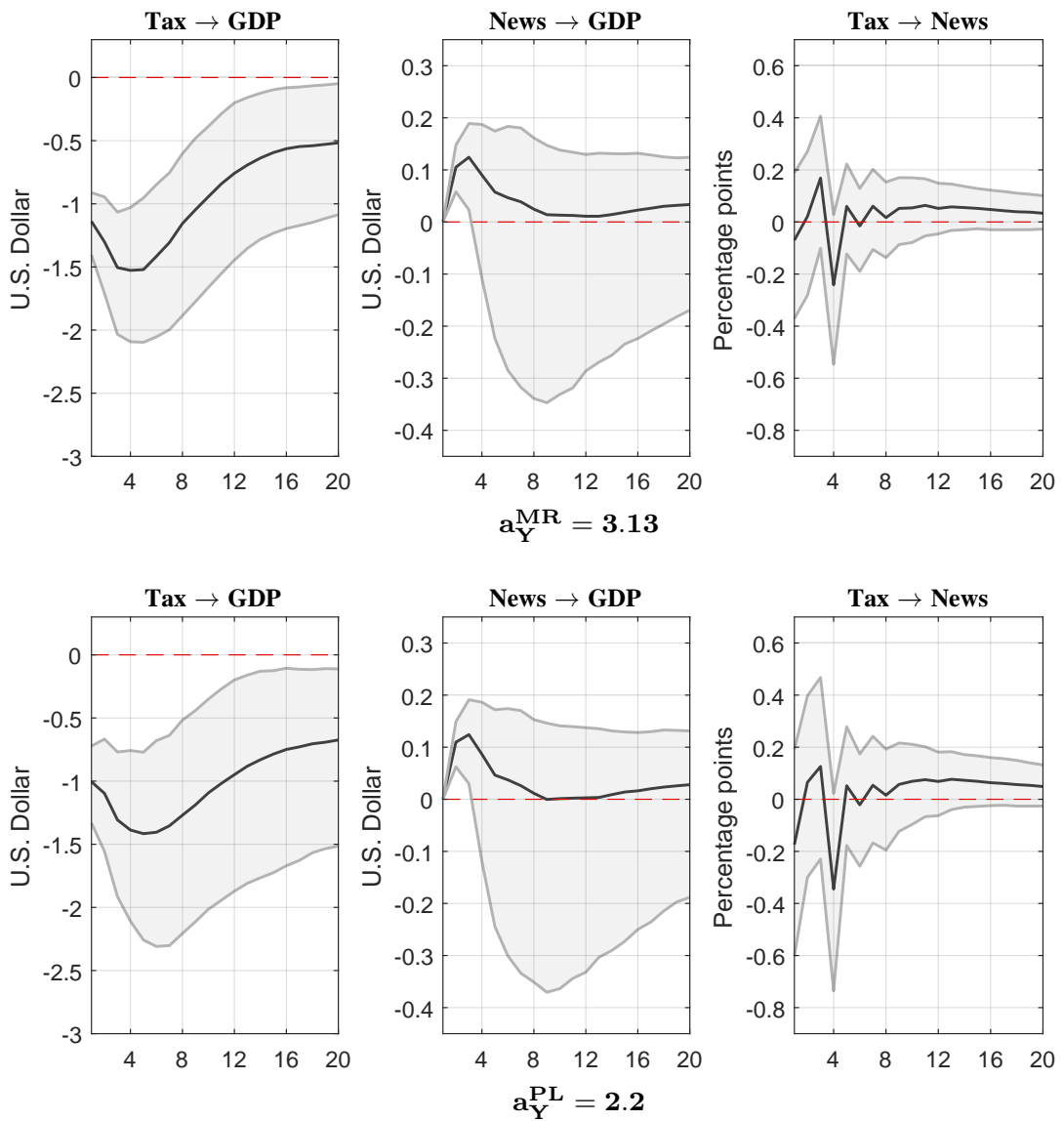

Figure 10: Impulse responses to a $\$ 1$ increase in taxes and a $1 \%$ point increase of tax policy news from the SVAR in (6) under alternative calibrations for the output elasticity of tax revenues. $a_{Y}^{M R}$ denotes a calibration according to Mertens and Ravn (2014) and $a_{Y}^{P L}$ according to estimates in Pereira and Lopes (2014). Shaded regions are the 90 percent confidence intervals, based on Monte Carlo simulation with 1000 iterations (assuming normality). 

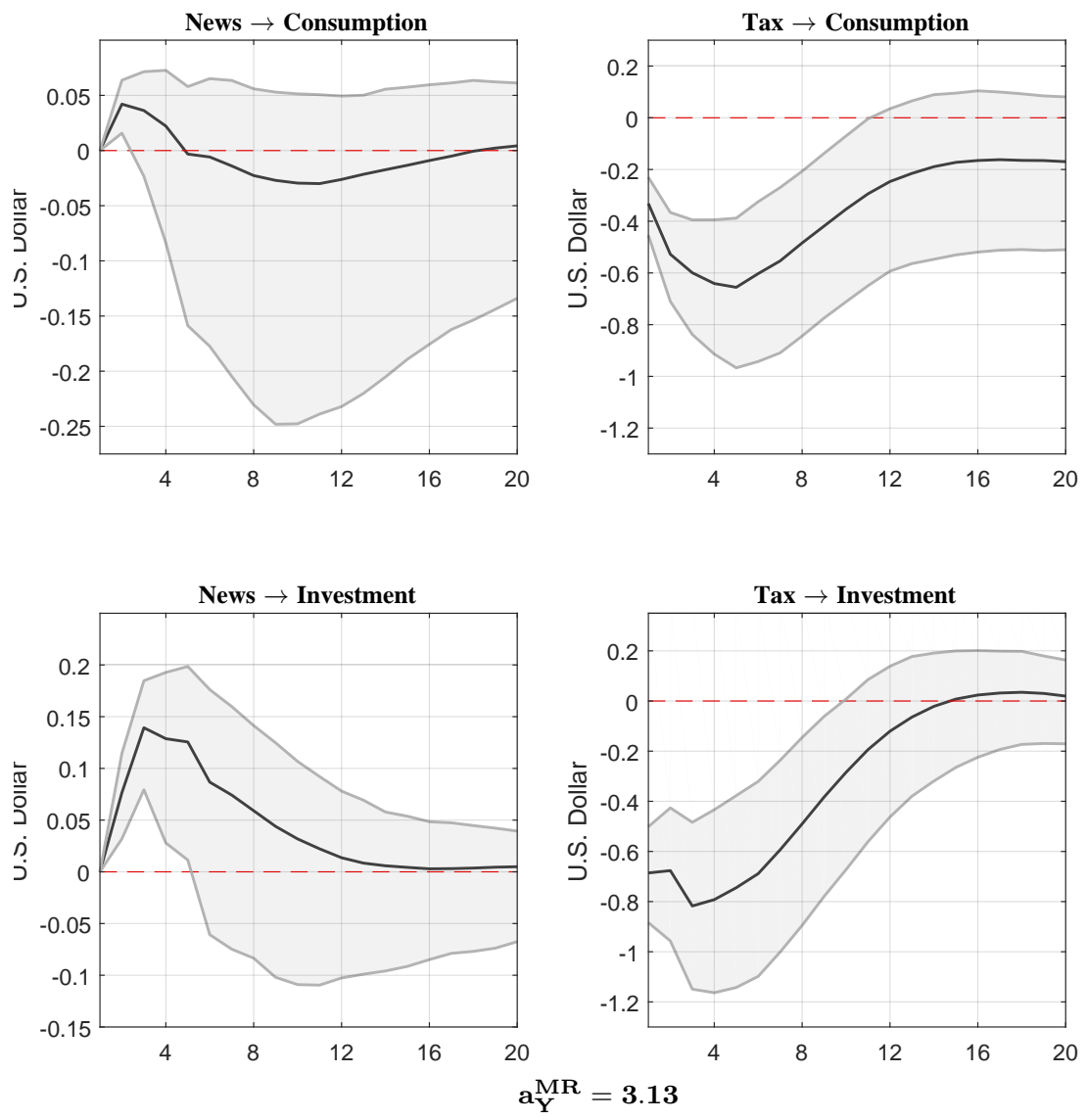

Figure 11: Impulse responses to a $1 \%$ point increase of tax policy news and a $\$ 1$ increase in taxes from the SVAR extension in 77 under the alternative calibration of $a_{Y}^{M R}=3.13$. MR signifies Mertens and Ravn (2014). Shaded regions are the 90 percent confidence intervals, based on Monte Carlo simulation with 1000 iterations (assuming normality). 

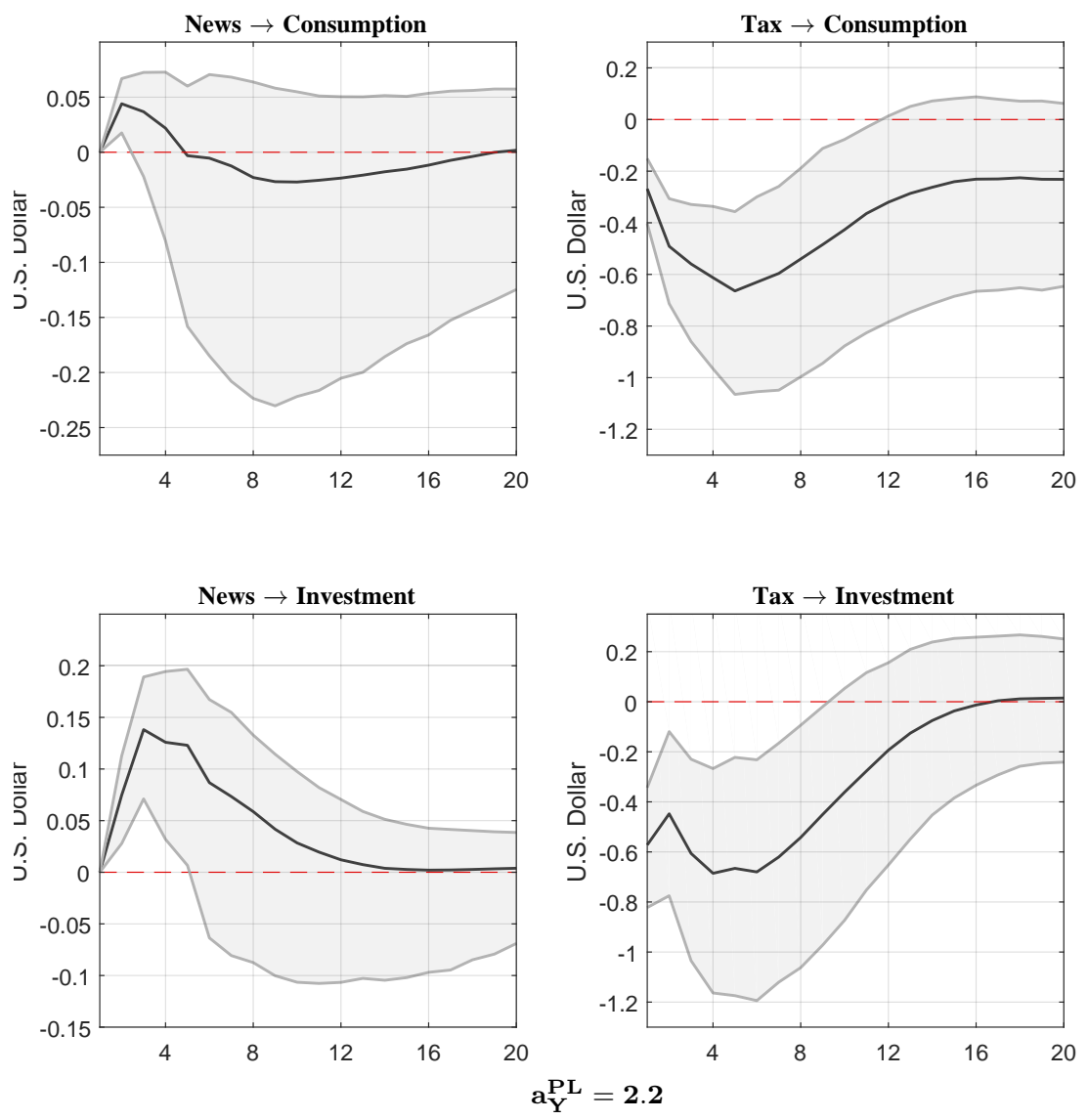

Figure 12: Impulse responses to a $1 \%$ point increase of tax policy news and a $\$ 1$ increase in taxes from the SVAR extension in (7) under the alternative calibration of $a_{Y}^{P L}=2.2$. PL signifies Pereira and Lopes (2014). Shaded regions are the 90 percent confidence intervals, based on Monte Carlo simulation with 1000 iterations (assuming normality). 

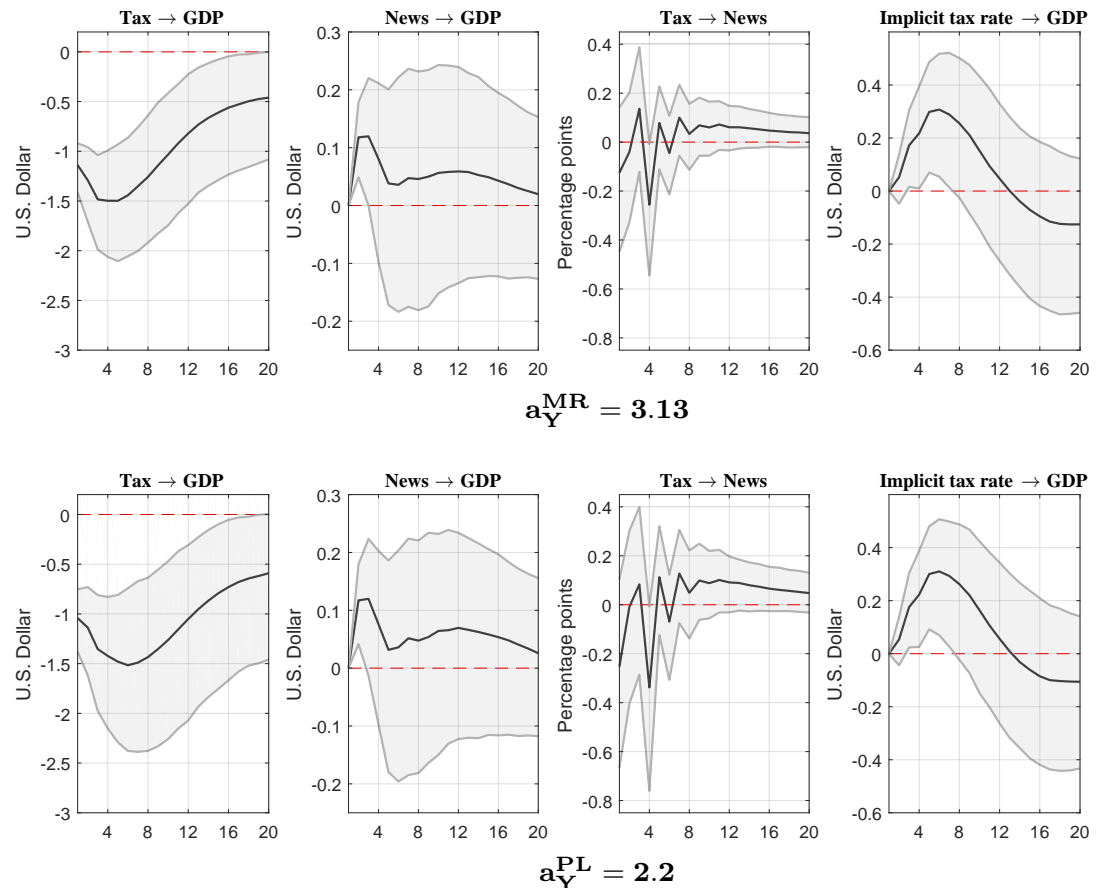

Figure 13: Impulse responses to a $\$ 1$ increase in taxes, $1 \%$ point increase of tax policy news, and $\$ 1$ increase in anticipated taxes from the SVAR, augmented with the implicit tax rate, under alternative calibrations for the output elasticity of tax revenues. $a_{Y}^{M R}$ denotes a calibration according to Mertens and Ravn (2014) and $a_{Y}^{P L}$ according to estimates in Pereira and Lopes (2014). Shaded regions are the 90 percent confidence intervals, based on Monte Carlo simulation with 1000 iterations (assuming normality). 